\title{
DETERMINATION OF BOND MODEL FOR 7-WIRE STRANDS IN PRETENSIONED CONCRETE BEAM
}

\author{
Vadzim Parkhats*, Rafae Krzywoń, Jacek Hulimka, Jan Kubica \\ Silesian University of Technology, Faculty of Civil Engineering, Department of Structural Engineering, \\ Akademicka 5, 44-100 Gliwice, Poland \\ * corresponding author: vadzpar036@student.polsl.pl
}

ABstract. A correct choice of a bond model for prestressing tendons is crucial for the right modelling of a structural behaviour of a pretensioned concrete structure. The aim of this paper is the determination of an optimal bond model for 7 -wire strands in a prestressed concrete beam produced in a precast concrete plant of Consolis Poland. ATENA 3D is used to develop finite element models of the beam that differ only in a bond stress-slip relationship of tendons. The bond stress-slip relationships for modelling are taken from the results of bond tests carried out by different researchers in previous years. Moreover, for comparison purposes, a simplified 2D model of the beam is created in Autodesk Robot. The strain distribution at the time of the strand release is found for each of the finite element models. The determined strain distributions are compared with the strain distribution in the beam established by an experimental test using a measuring system based on a digital image correlation. On the basis of the comparison results, the most appropriate bond models for 7 -wire strands used in the beam are identified.

KEYWORDS: Bond stress-slip relationship, digital image correlation, end zone, prestressed concrete, pretensioned concrete beam, strand release.

\section{INTRODUCTION}

As is known, the prestressing force is transferred to the concrete of a pretensioned member by the bond between the concrete and the prestressing steel [1]. Therefore, an accurate definition of a bond model for prestressing tendons in finite element modelling of pretensioned concrete structures is key for the determination of correct results. Unfortunately, a bond stress-slip relationship for a prestressing tendon is omitted from most design standards. Model Code 2010 [2] contains bond models for ribbed and plain reinforcing bars, but not for prestressing strands.

Digital image correlation (DIC) is a non-contact optical technique for measuring strain and displacement [3]. In recent years, this measurement technique has been used more and more often in various fields of study: civil engineering [4], applied mechanics [5], biology [6], aerospace engineering [7] and others [8, 9 . In particular, it should be noted that the DIC technique is nowadays used in the research of prestressed concrete [10-15].

In this paper, a review of bond models for tendons found in the literature is done. Moreover, an experimental test carried out with the help of a DIC measurement system and consisting in a determination of strain distribution in the end zone of a pretensioned concrete beam at the time of the strand release is described. Bond models found in the literature are applied in finite element modelling of the beam used in the experimental test to establish the most appropriate ones. The appropriateness of the bond models is evaluated by the comparison of the strain distributions determined in specific points on the side surface of the beam by means of DIC measurements and finite element modelling. The best fitting bond models will be additionally verified on other pretensioned concrete structures of the same manufacturer in the future. Furthermore, it is also planned to carry out bond tests for deducing our own bond model for the used 7-wire strands.

\section{LiterATURE REVIEW OF BOND MODELS FOR STRANDS}

Bond models for 7-wire strands found in the literature are presented in this section. Bond models for other types of tendons are omitted, since only 7 -wire strands were used in the beam analysed in the experimental test.

Balazs [16] presented the bond stress-slip relationship 1 based on results of pull-out tests with 7 -wire strands with a diameter of $12.8 \mathrm{~mm}$. The specified concrete strength at transfer was $f_{c i}^{\prime}=40 \mathrm{MPa}$.

$$
\tau=\psi c\left(f_{c i}^{\prime}\right)^{0.5}\left(S / d_{b}\right)^{b}
$$

where: $\tau$ is the bond stress $[\mathrm{MPa}] ; S$ is the slip [m]; $d_{b}$ is the strand diameter [m]; $\psi$ is the factor [-] for the upper bound $\left(\psi_{0.95}=1.35\right)$, the mean value $\left(\psi_{m}\right.$ $=1.00)$ and the lower bound $\left(\psi_{0.05}=0.65\right)$ of bond stresses; $c$ and $b$ are the experimental constants; for $d_{b}=12.8 \mathrm{~mm}: c=2.055 \mathrm{MPa}^{0.5}$ and $b=0.25$.

Oh et al. [17] carried out bond tests for $12.7 \mathrm{~mm}$ and $15.2 \mathrm{~mm}$ strands using concrete with the strength 


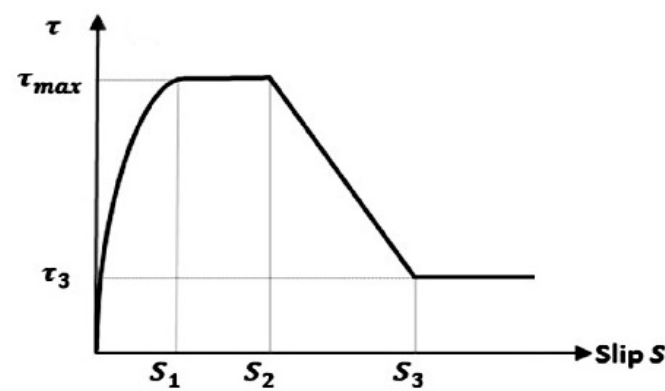

(A).

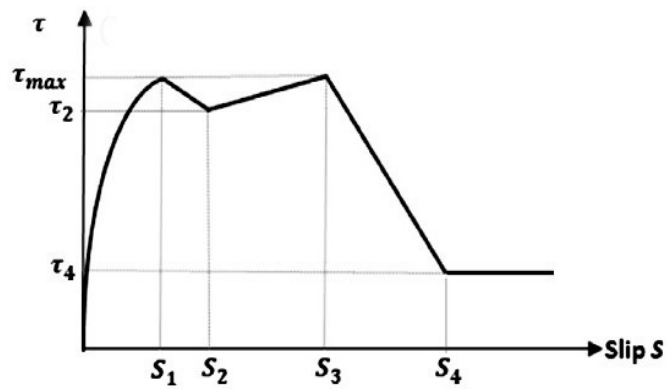

(в).

Figure 1. Bond stress-slip relationship [20: (A) for ribbed bars in the case of a pull-out failure according to Model Code 2010, (B) for 7-wire smooth strands according to the Equations 8

$f_{c i}^{\prime}=32.71-35.50 \mathrm{MPa}$. The following equation was obtained:

$$
\tau=C\left(S / d_{b}\right)^{b}
$$

where: $C$ and $b$ are experimental constants; for $d_{b}$ $=12.7 \mathrm{~mm}: C=13.787 \mathrm{MPa}$ and $b=0.3301$, for $d_{b}$ $=15.2 \mathrm{~mm}: C=9.331 \mathrm{MPa}$ and $b=0.2688$.

Lim et al. [18 presented a bond stress-slip relationship obtained by a measurement of strains in pretensioned members with the help of strain gauges. Their relationship for $15.2 \mathrm{~mm}$ strands is identical to the Equation 1 with $\psi=1.00$, but the values of the experimental constants are different: $c=10.7 \mathrm{MPa}^{0.5}$ and $b=0.27$.

Orr et al. 19] carried out pull-out tests for both unstressed and stressed $15.2 \mathrm{~mm}$ strands. The specified concrete strength at the transfer was $f_{c i}^{\prime}=54.2$ MPa. Their model is based on the bond stress-slip relationship 36 for ribbed bars in the case of a pull-out failure presented in Model Code 2010 [2] (Figure 1a).

$$
\begin{gathered}
\tau=\tau_{\max }\left(S / S_{1}\right)^{\alpha} \text { for } 0 \leq S \leq S_{1} \\
\tau=\tau_{\max } \text { for } S_{1} \leq S \leq S_{2} \\
\tau=\tau_{\max }-\left(\tau_{\max }-\tau_{f}\right)\left(S-S_{2}\right) /\left(S_{3}-S_{2}\right) \\
\text { for } S_{2} \leq S \leq S_{3}
\end{gathered}
$$

$$
\tau=\tau_{f} \text { for } S>S_{3}
$$

The following values of the parameters of their model were proposed: $\alpha=0.5 ; S_{1}=S_{2}=S_{3}=$ $0.1 \mathrm{~mm}$ for stressed strands and $S_{1}=S_{2}=S_{3}=$ $2 \mathrm{~mm}$ for unstressed strands. The Equation 7 is stated for the determination of the bond stress: where: $\delta_{1}$ accounts for the reduction in the bonded perimeter in specimens with reduced cover $[-] ; \delta_{2}$ accounts for the confinement from cover or transverse reinforcement $[-] ; f_{c m}$ is the mean concrete cylinder strength of the specimen [MPa].

As opposed to the above-mentioned researchers, Khalaf and Huang [20] developed an analytical bond model for both 3 -wire and 7 -wire strands. It was validated by a comparison of its results and the results of experimental tests. The model considers the surface condition of a strand, the geometry and the number of wires, the concrete parameters, and the influence of elevated temperatures. The model is based on the Model Code 2010 relationship (Eq. 3.6), but is modified in the case of 7 -wire smooth strands (Figure 1):

$$
\begin{gathered}
\tau=\tau_{\max }\left(S / S_{1}\right)^{\alpha} \text { for } 0 \leq S \leq S_{1} \\
\tau=\tau_{\max }-\left(\tau_{\max }-\tau_{2}\right)\left(S-S_{1}\right) /\left(S_{2}-S_{1}\right) \\
\text { for } S_{1} \leq S \leq S_{2}
\end{gathered}
$$

$$
\begin{array}{r}
\tau=\tau_{2}+\left(\tau_{\max }-\tau_{2}\right)\left(S-S_{2}\right) /\left(S_{3}-S_{2}\right) \\
\text { for } S_{2} \leq S \leq S_{3}
\end{array}
$$

$$
\begin{array}{r}
\tau=\tau_{\max }-\left(\tau_{\max }-\tau_{4}\right)\left(S-S_{3}\right) /\left(S_{4}-S_{3}\right) \\
\text { for } S_{3} \leq S \leq S_{4}
\end{array}
$$

$$
\tau=\tau_{f} \text { for } S>S_{4}
$$

The following parameters are considered in the case of 7-wire smooth strands: $S_{1}=0.25 \mathrm{~mm} ; S_{2}$ $=0.5 \mathrm{~mm} ; S_{3}=3.5 \mathrm{~mm} ; S_{4}=8 \mathrm{~mm} ; \tau_{2}=0.75 \tau_{\max } ;$ $\tau_{4}=0.35 \tau_{\max }$. The bond stress is calculated in accordance with the Equation 13

$$
\tau_{\max }=\tau_{f}=\delta_{1} \delta_{2} 0.70\left(f_{c m}\right)^{0.5}
$$

$$
\tau_{\max }=T_{b} / A_{b}
$$




\begin{tabular}{lc}
\hline Cement CEM I 52,5R Lafarge & 414 \\
Limestone powder Cemex Rudniki & 58 \\
Sand $(0-2 \mathrm{~mm})$ & 681 \\
Crushed granodiorite $(2-8 \mathrm{~mm})$ & 474 \\
Crushed granodiorite $(8-16 \mathrm{~mm})$ & 664 \\
Water & 116.6 \\
Admixture Sika $34 \mathrm{RS}$ & 3.68 \\
\hline
\end{tabular}

TABLE 1. Composition of concrete $\left[\mathrm{kg} / \mathrm{m}^{3}\right]$.

\begin{tabular}{lcc}
\hline Property & Value & Standard deviation \\
\hline Cube compressive strength [MPa] & 56.6 & 0.50 \\
Cylinder compressive strength [MPa] & 48.32 & 1.09 \\
Mean tensile strength [MPa] & 3.98 & - \\
Modulus of elasticity [GPa] & 25.81 & 0.27 \\
Poisson's ratio [-] & 0.19 & 0.016 \\
Strain at failure [\%o] & 2.72 & 0.20 \\
Plastic part of strain [\%o] & 0.85 & 0.15 \\
Tensile strain at failure [\%o] & 0.154 & - \\
Density $\left[\mathrm{kg} / \mathrm{m}^{3}\right.$ ] & 2444 & - \\
\hline
\end{tabular}

TABLE 2. Average properties of concrete at the time of strand release.

where: $T_{b}$ is the maximum bond force $[\mathrm{MN}]$ found according to the Equation $15 A_{b}$ is the contact area between the strand and the concrete $\left[\mathrm{m}^{2}\right]$;

$$
A_{b}=\pi d_{b} L_{b}
$$

where $L_{b}$ is the embedded length of the strand [m].

$$
\begin{aligned}
T_{b}=\left[\mu v_{c} d_{w} l_{w} n\right. \\
\left.\quad+0.6 \pi d_{w} l_{w} n\left(C^{\prime}+\mu \sigma_{n}\right)\right] / \cos \theta
\end{aligned}
$$

where: $d_{w}, l_{w}, n, \theta=9^{\circ}$ are the diameter $[\mathrm{m}]$, the length $[\mathrm{m}]$, the number [-], and the pitch angle of the outer wires, respectively; $\mu$ is the coefficient of friction between the concrete and the steel $[-] ; C^{\prime}$ is the cohesion between the concrete and the steel $[-]$; for 7 -wire smooth strands $\mu=0.4$ and $C^{\prime}=1.3 ; \sigma_{n}$ is the normal stress perpendicular to the strand axes [MPa]; $v_{c}$ is the shear strength of the shear keys in the concrete mass $[\mathrm{MPa}] ; v_{c}$ should not be greater than $0.2 f_{c}^{\prime}$, where $f_{c}^{\prime}$ is the concrete compressive strength [MPa]; for the pull-out bond $\left(\sigma_{n}=0\right) v_{c}$ is calculated according to the Equation 16 .

$$
v_{c}=f_{t}\left[f_{c}^{\prime} / f_{t}+2-2\left(1+f_{c}^{\prime} / f_{t}\right)^{0.5}\right]^{0.5}
$$

where $f_{t}$ is the concrete tensile strength $[\mathrm{MPa}]$.

\section{EXPERIMENTAL TEST}

In this section, the experimental test carried out in a precast concrete plant of Consolis Poland is described. It consisted in the measurement of strains in the end region of the prestressed concrete beam at the time of the strand release by a DIC system. The test results are necessary to verify strain distributions in the finite element models of the beam.

\subsection{SPECIMEN DESCRIPTION}

The 11.66-metre long pretensioned concrete beam (Figures 2 and 3 was used for the test. The cross section was I-shaped in the central part, whereas the anchorage zone was equipped with an end block. Three horizontal openings in the central part and four vertical openings in the end zones were provided.

Twenty prestressing tendons with a diameter of $15.7 \mathrm{~mm}$ made of steel Y1860S7 were used in the beam. Their tension was $1250 \mathrm{MPa}$. It should be noted that two of them had a shielding two metres long. The strands were cut with an acetylene torch in a sequence shown in Figure 2b

The stirrups, 8 and $10 \mathrm{~mm}$ in diameter, were made of steel B500. Their spacing in the end region was not greater than $95 \mathrm{~mm}$.

The beam was made of concrete of the strength class C50/60. Its composition is presented in Table 1 . The mechanical properties at the time of the strand release (44 hours after the pouring) were determined with the help of additional tests on the cubic and cylindrical concrete specimens and are summarised in Table 2,

\subsection{TEST PROCEDURE}

The side surface of the beam was covered with paint and recorded during the strand release by a DIC measurement system. On the basis of the obtained images, strain distribution was established in the 2.4-metrelong end region. The GOM ARAMIS system equipped 


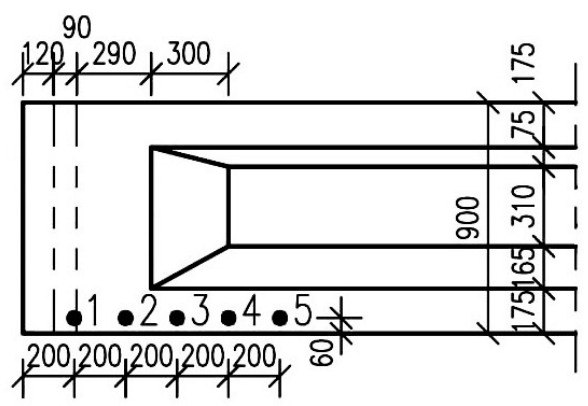

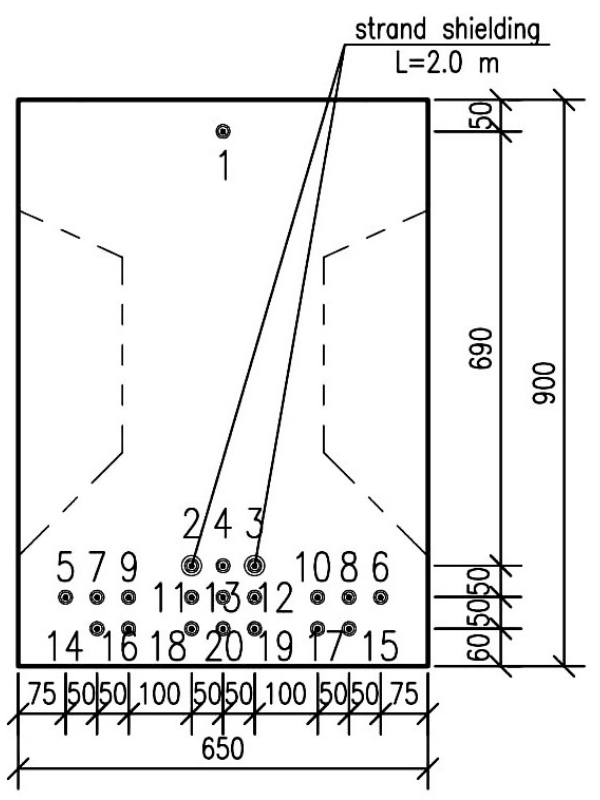

(в).

(A).

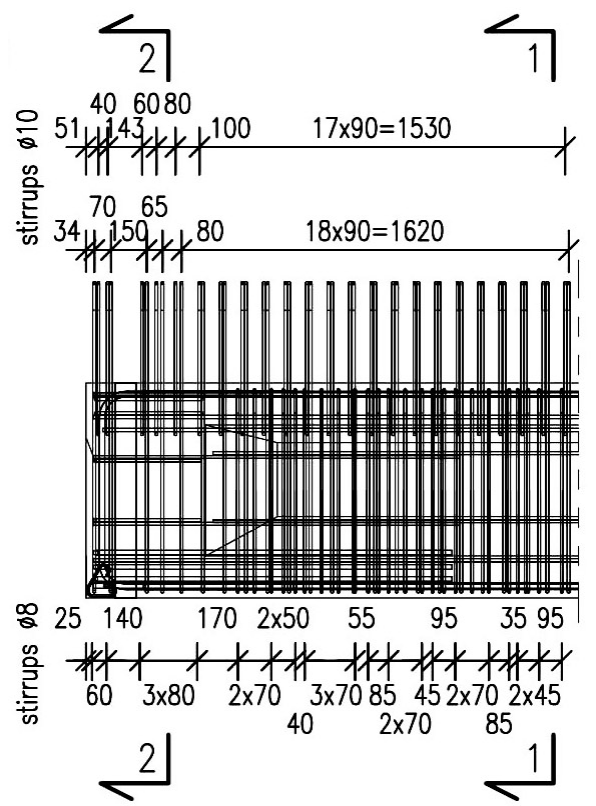

(c).

Figure 2. Pretensioned concrete beam: a) a side view of the end region and the location of virtual extensometers, b) the arrangement of prestressing steel and the order of the strand release, c) the reinforcing steel in the end zone.
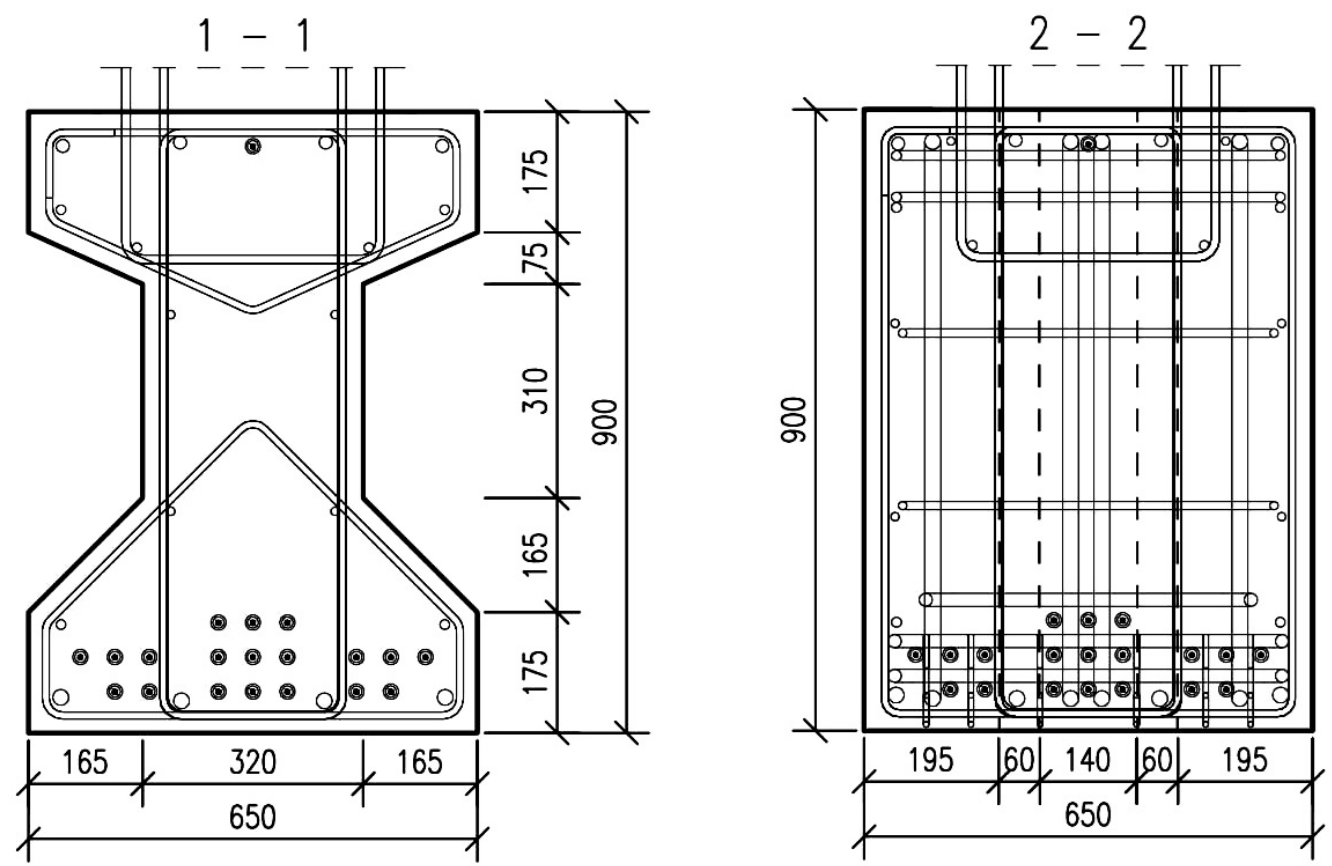

Figure 3. Sections $1-1$ and $2-2$ in the end region (see also Figure 2c). 


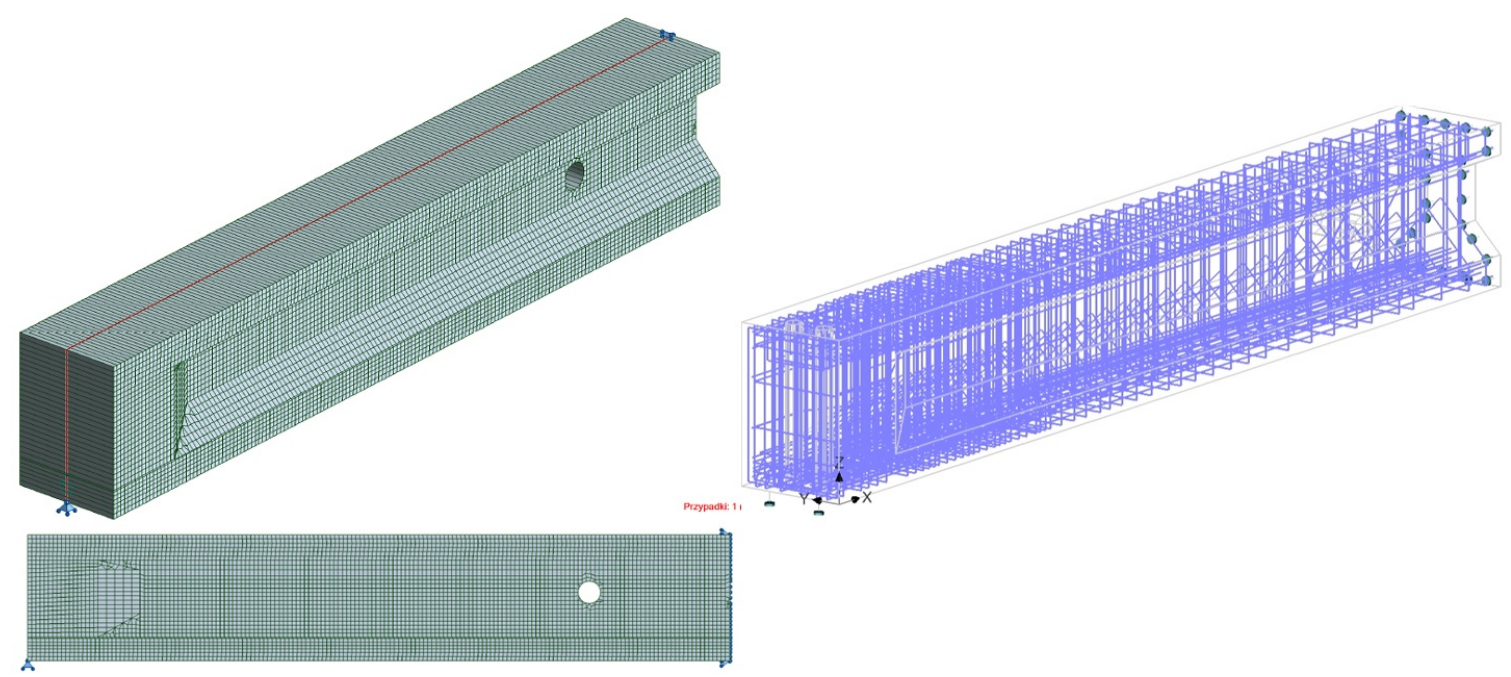

Figure 4. Finite element models created in Autodesk Robot (on the left) and ATENA 3D (on the right).

with two prime-lens 6-megapixel cameras (24 mm focal length) was used. The recording frequency was $4 \mathrm{~Hz}$.

\section{Finite ElEMENT MODELling}

ATENA 3D and Autodesk Robot are used for the finite element modelling. Because of the symmetry of the specimen, half of the beam is modelled (Figure 4).

Seven finite element models created in ATENA 3D consider both the prestressing and the reinforcing steel, openings in the beam, and the order of the strand release. The concrete is defined by the material " $3 \mathrm{D}$ Nonlinear Cementitious 2". The mesh size is $5 \mathrm{~cm}$. The models differ only in a bond stress-slip relationship for prestressing tendons. The relationships for strands deduced by [16, 17, 19, 20] are applied. Additionally, the Model Code 2010 relationship (3 6) for ribbed bars in the case of a pull-out failure is used to evaluate its appropriateness for 7 -wire strands. The relationship of Lim et al. [18] is omitted, because it leads to questionable results.

One simplified 2D finite element model based on linear elastic properties of concrete is developed in Autodesk Robot. The reinforcement and openings in the beam are omitted. Prestressing is simulated by a linear increase of negative temperature over the transmission length of the beam (i. e., approximately $780 \mathrm{~mm})$. The value of the transmission length is calculated with the help of the simplified method presented in [21].

\section{Results AND DISCUSSION}

The small values of strains during the strand release lead to difficulties in interpretation of the results obtained by ARAMIS.

Firstly, instead of using deformation maps, the results are presented with the help of virtual extensometers $200 \mathrm{~mm}$ long. The location of the longitudinal extensometers is shown in Figure 2a They are situated on the side surface of the beam in the characteristic points of strain variation, namely on the level of the bottom row of strands (points 1, 2, 3, 4, and 5). The location of the extensometers is chosen so that they evenly cover the transmission length.

The other problem are great fluctuations of the values in the strain distribution diagrams. Therefore, the weighted moving average method is used to decrease the fluctuations: the strains in the diagrams are averaged out for seven previous values and seven subsequent ones.

The transverse strain distributions in the end block are not presented in the paper, because they are characterised by such significant fluctuations that the verification of the models using these results seems pointless.

The longitudinal strain distributions in the characteristic points of the beam (Figure 2 ) obtained by ARAMIS and finite element modelling are shown in Figure 5 The horizontal axis corresponds to the space of time when the strand release was carried out.

It is observed that, with the increase of the distance from the end of the beam, all the finite element models overestimate the strains in comparison with the values obtained by ARAMIS approximately until the time when the bottom row of strands starts to be released (between 125 and $150 \mathrm{~s}$, especially at the point 5, a characteristic leap is seen). After this moment, the values obtained by the modelling and the experimental test are close. The possible cause is that between 125 and $150 \mathrm{~s}$, a detachment of the concrete from the formwork happens, so the structural behaviour of the beam is changed. Therefore, in the finite element modelling, the bottom surface of the beam should be restrained from moving in a vertical direction over the full length of the beam until the moment of the detachment. After the detachment, only the place of junction of the end and bottom surfaces should be restrained in this way (as is done in the analysed finite element models - see Figure 4). This explanation 

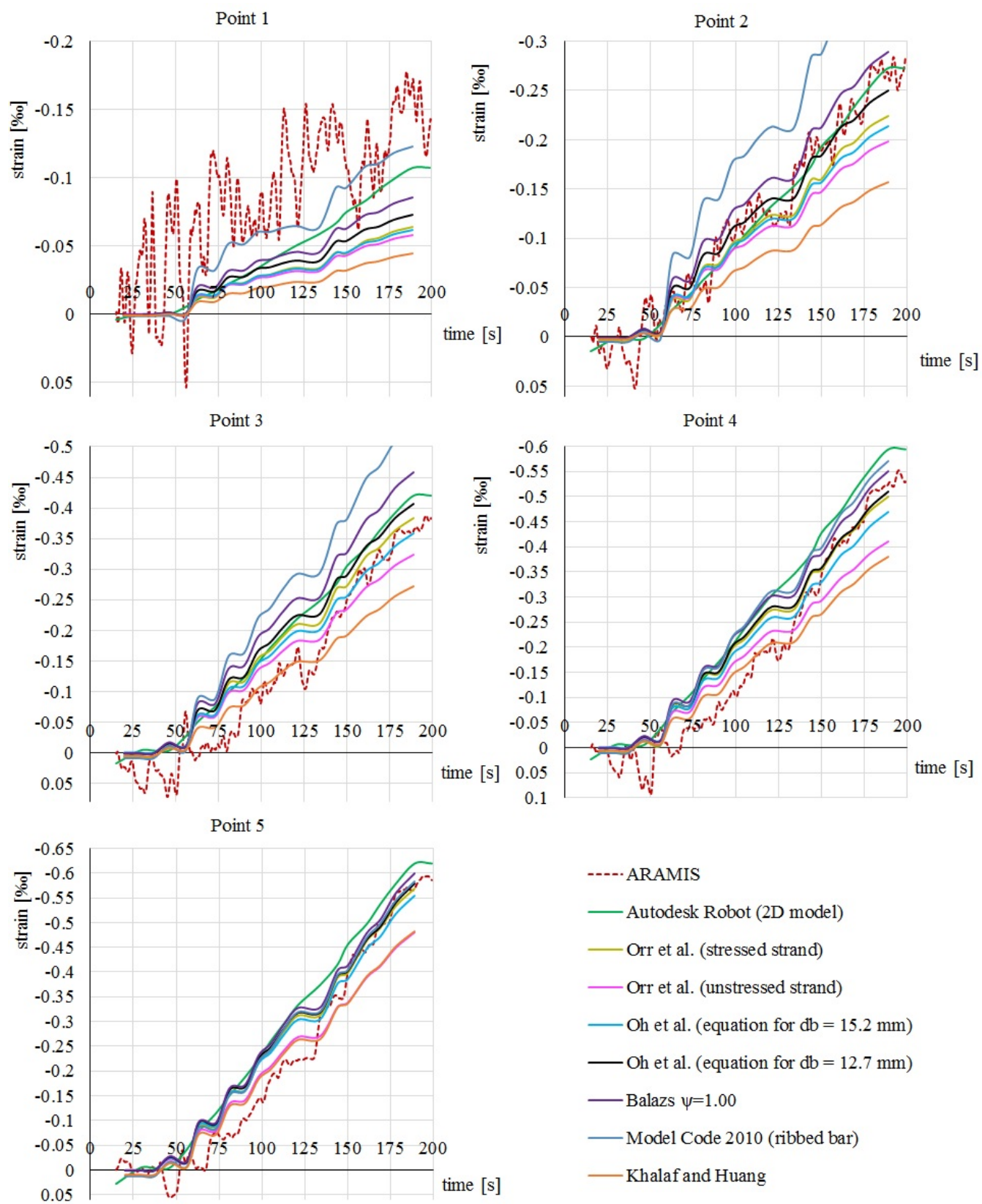

FiguRE 5. Longitudinal strains in the end zone during strand release (location of the points is shown in Figure 2a.

is confirmed by the longitudinal strain distributions presented in Figure 6, where the strains obtained by ARAMIS are compared with the strains obtained with the help of the finite element model restrained from moving in a vertical direction over the full length. It can be seen that the values in the diagrams are similar until the time between 125 and 150 s, i.e., until the moment of the detachment.

Coefficients of determination between the strains according to ARAMIS and the predicted strains are presented in Tables 3 and 4 On the basis of the strain distributions (Figures 5, 7) and the coefficients of correlation (Tables 3 4, it is established that the finite element models using the bond stress-slip relationships of Model Code 2010 [2 for ribbed bars, Orr et al. [19] for unstressed strands, and Khalaf and Huang [20] give results that are significantly different than those obtained with the help of ARAMIS.

The finite element model based on the Model Code 2010 relationship overestimates the values of the strains, whereas the models using the relationships of Orr et al. 19 for unstressed strands and Khalaf and Huang [20] underestimate them. In the case of the model based on the Model Code 2010 relationship, the difference has been expected, since this relationship is developed for ribbed reinforcing bars, but not for prestressing tendons. The inappropriateness of the model using the relationship of Orr et al. [19] for unstressed strands indicates that the prestressing of strands in bond tests is crucial for deducing a realistic bond stress-slip relationship. Concerning the model based on the relationship of Khalaf and Huang [20, it 

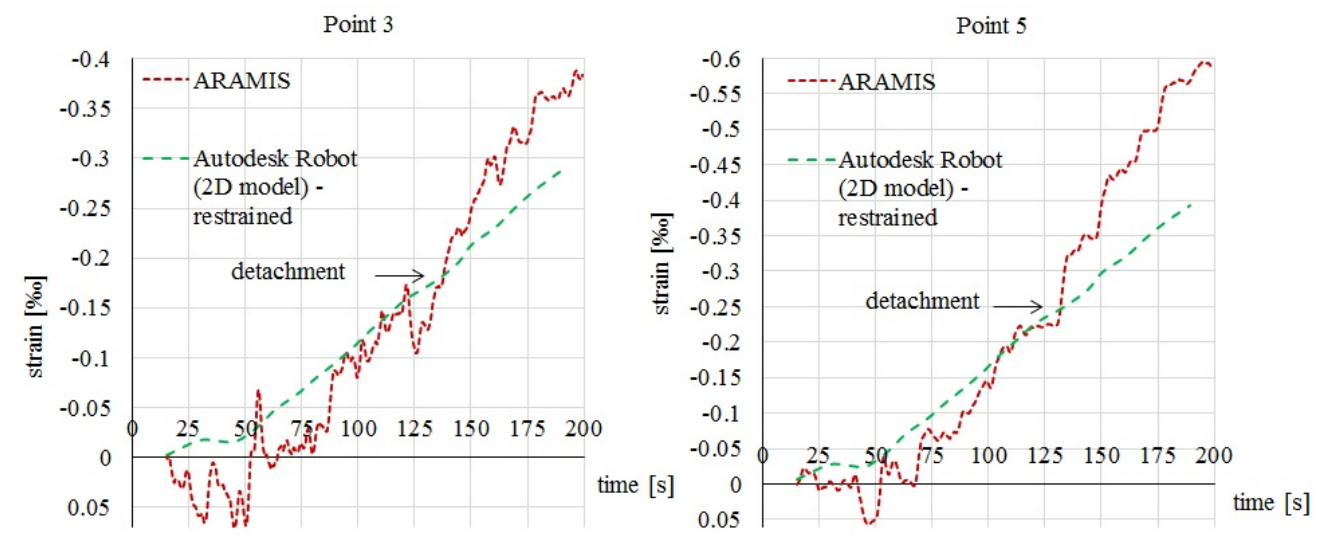

FiguRE 6. Longitudinal strains in the end zone during strand release - moment of the detachment of the concrete from the formwork.

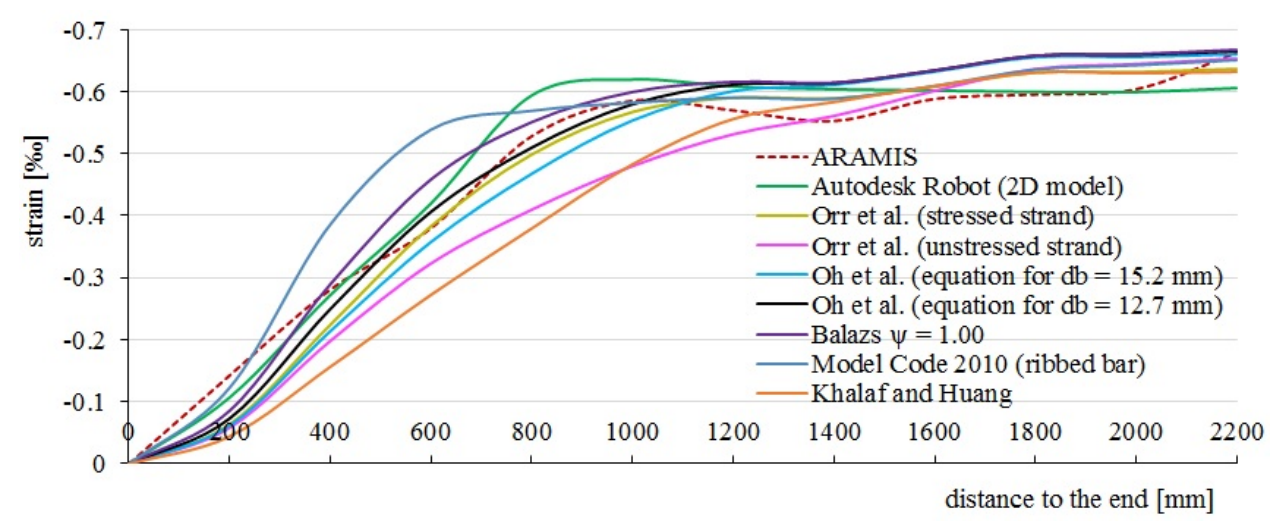

FIGURE 7. Longitudinal strains along the beam length on the level of the bottom row of strands after release of all the tendons.

\begin{tabular}{lccccc}
\hline \multirow{2}{*}{ Bond model } & \multicolumn{5}{c}{ Points } \\
\cline { 2 - 6 } & 1 & 2 & 3 & 4 & 5 \\
\hline Autodesk Robot (2D Model) & 0.505 & 0.978 & 0.962 & 0.974 & 0.971 \\
Orr et al. (stressed strand) & 0.538 & 0.975 & 0.944 & 0.953 & 0.959 \\
Orr et al. (unstressed strand) & 0.546 & 0.974 & 0.942 & 0.954 & 0.959 \\
Oh et al. (equation for $\left.d_{b}=15.2 \mathrm{~mm}\right)$ & 0.546 & 0.975 & 0.946 & 0.957 & 0.960 \\
Oh et al. (equation for $\left.d_{b}=12.7 \mathrm{~mm}\right)$ & 0.548 & 0.974 & 0.945 & 0.956 & 0.960 \\
Balazs $\psi=1.00$ & 0.549 & 0.973 & 0.943 & 0.956 & 0.961 \\
Model Code 2010 (ribbed bar) & 0.552 & 0.968 & 0.942 & 0.957 & 0.961 \\
Khalaf and Huang & 0.545 & 0.977 & 0.949 & 0.958 & 0.960 \\
\hline
\end{tabular}

TABLE 3. Coefficient of determination between the strains according to ARAMIS and the predicted strains (for the strains shown in Figure 5 .

\begin{tabular}{lc}
\hline Bond model & Coefficient of determination \\
\hline Autodesk Robot (2D Model) & 0.954 \\
Orr et al. (stressed strand) & 0.980 \\
Orr et al. (unstressed strand) & 0.937 \\
Oh et al. (equation for $d_{b}=15.2 \mathrm{~mm}$ ) & 0.966 \\
Oh et al. (equation for $\left.d_{b}=12.7 \mathrm{~mm}\right)$ & 0.976 \\
Balazs $\psi=1.00$ & 0.971 \\
Model Code 2010 (ribbed bar) & 0.896 \\
Khalaf and Huang & 0.924 \\
\hline
\end{tabular}

TABLE 4. Coefficient of determination between the strains according to ARAMIS and the predicted strains (for the strains presented in Figure 7). 
is difficult to explain the cause of the different results. It is interesting to note that this is the only analytically developed relationship in the literature review, as opposed to the others determined by experimental tests. Experimental tests on more pretensioned concrete structures with different design parameters should be carried out to draw definitive conclusions about appropriateness of the analysed bond stress-slip relationships for the strands and concrete used.

\section{Conclusions}

In this paper, bond stress-slip relationships for 7wire strands of different researchers are analysed to evaluate their appropriateness for the use in finite element modelling of the pretensioned concrete beam made in a precast concrete plant of Consolis Poland. The assessment is done by a comparison of the strain distributions in the beam found by ARAMIS and the finite element modelling.

The following conclusions are drawn:

(1.) The longitudinal strain distributions in the finite element models based on the bond stress-slip relationships of Balazs [16], Orr et al. 19] (for stressed strands), and $\mathrm{Oh}$ et al. [17] are fairly similar to the results of the DIC measurements. Moreover, using the simplified model developed in Autodesk Robot gives satisfactory results as well. However, it is worth noting that the relationships of $\mathrm{Oh}$ et al. 17] do not consider the concrete strength at the transfer, so that the satisfying similarity might be accidental. Neglecting the concrete strength at the transfer restricts their applicability to the finite element modelling of pretensioned concrete structures. In addition, it is found that the finite element models based on the bond relationships of Orr et al. 19 for unstressed strands and Khalaf and Huang [20] underestimate the strains, whereas the model using the Model Code 2010 relationship for ribbed bars overestimates them. However, these findings have to be additionally verified on the basis of experimental tests on other pretensioned concrete members that are planned in the future. Besides, bond tests utilising the same prestressing strands and concrete mix are proposed as a direction for a future research.

(2.) The strain distributions obtained by ARAMIS are characterised by great fluctuations that complicate the analysis of the results. It concerns the transverse strain distributions. In future tests, the scanned region is planned to be reduced to increase the resolution and make the results more legible.

(3.) It is established that the structural behaviour of a pretensioned concrete beam might change during the strand release because of the detachment of the concrete from the formwork. Thus, a finite element model of a pretensioned concrete beam should be restrained from moving in a vertical direction differently before and after the detachment.

\section{REFERENCES}

[1] C. W. Dolan, H. R. Hamilton. Prestressed Concrete. Springer International Publishing, 2019. https://doi.org/10.1007/978-3-319-97882-6.

[2] fib Model Code for Concrete Structures 2010. Ernst \& Sohn, Berlin, 2013. https://doi.org/10.1002/9783433604090

[3] N. McCormick, J. Lord. Digital image correlation. Materials Today 13(12):52-54, 2010. https://doi.org/10.1016/S1369-7021(10)70235-2

[4] M. A. Sutton, F. Matta, D. Rizos, et al. Recent progress in digital image correlation: Background and developments since the $2013 \mathrm{~W}$ M Murray lecture. Experimental Mechanics 57:1-30, 2017. https://doi.org/10.1007/s11340-016-0233-3.

[5] M.-T. Lin, C. Furlong, C.-H. Hwang (eds.). Advancement of Optical Methods $\&$ Digital Image Correlation in Experimental Mechanics. Springer International Publishing, 2021. https://doi.org/10.1007/978-3-030-59773-3.

[6] E. B. Dolan, S. W. Verbruggen, R. A. Rolfe. Mechanobiology in Health and Disease, chap. 1 -Techniques for studying mechanobiology, pp. 1-53. Academic Press, 2018. https: //doi.org/10.1016/B978-0-12-812952-4.00001-5

[7] A. Pagani, R. Azzara, E. Carrera, E. Zappino. Static and dynamic testing of a full-composite VLA by using digital image correlation and output-only ground vibration testing. Aerospace Science and Technology 112:106632, 2021. https://doi.org/10.1016/j.ast.2021.106632.

[8] B. Pan. Digital image correlation for surface deformation measurement: historical developments, recent advances and future goals. Measurement Science and Technology 29(8):082001, 2018. https://doi.org/10.1088/1361-6501/aac55b

[9] J.-N. Perie, J.-C. Passieux (eds.). Advances in Digital Image Correlation (DIC), vol. Special Issue of Applied Sciences. 2020. https://doi.org/10.3390/books978-3-03928-515-0

[10] B. Omondi, D. G. Aggelis, H. Sol, C. Sitters. Improved crack monitoring in structural concrete by combined acoustic emission and digital image correlation techniques. Structural Health Monitoring 15(3):359-378, 2016. https://doi.org/10.1177/1475921716636806.

[11] D. Zhu, S. Liu, Y. Yao, et al. Effects of short fiber and pre-tension on the tensile behavior of basalt textile reinforced concrete. Cement and Concrete Composites 96:33-45, 2019.

https://doi.org/10.1016/j.cemconcomp.2018.11.015

[12] E. Martinelli, A. Hosseini, E. Ghafoori, M. Motavalli. Behavior of prestressed CFRP plates bonded to steel substrate: Numerical modeling and experimental validation. Composite Structures 207:974-984, 2019. https://doi.org/10.1016/j.compstruct.2018.09.023 
[13] C. Lakavath, S. S. Joshi, S. S. Prakash. Investigation of the effect of steel fibers on the shear crack-opening and crack-slip behavior of prestressed concrete beams using digital image correlation. Engineering Structures 193:28-42, 2019.

https://doi.org/10.1016/j.engstruct.2019.05.030.

[14] A. B. Sturm, P. Visintin, R. Seracino, et al. Flexural performance of pretensioned ultra-high performance fibre reinforced concrete beams with CFRP tendons. Composite Structures 243:112223, 2020. https://doi.org/10.1016/j.compstruct.2020.112223

[15] H. Zhao, B. Andrawes. Innovative prestressing technique using curved shape memory alloy reinforcement. Construction and Building Materials 238:117687, 2020. https: //doi.org/10.1016/j.conbuildmat.2019.117687.

[16] G. Balazs. Transfer control of prestressing strands. PCI Journal 37(6):60-71, 1992. https://doi.org/10.15554/pcij.11011992.60.71.

[17] B. H. Oh, E. S. Kim, Y. C. Choi. Derivation of development length in pretensioned prestressed concrete members. Journal of the Korea Concrete Institute 12(6):3-11, 2000.

https://doi.org/10.22636/JKCI.2000.12.6.3

[18] S. N. Lim, Y. C. Choi, B. H. Oh, et al. Bond characteristics and transfer length of prestressing strand in pretensioned concrete structures. In FraMCoS-8 VIII International Conference on Fracture Mechanics of Concrete and Concrete Structures, pp. 121-128. 2013. http://www.framcos.org/FraMCoS-8/p348.pdf.

[19] J. J. Orr, A. Darby, T. Ibell, et al. Anchorage and residual bond characteristics of 7 -wire strand.

Engineering Structures 138:1-16, 2017.

https://doi.org/10.1016/j.engstruct.2017.01.061.

[20] J. Khalaf, Z. Huang. Analysis of the bond behaviour between prestressed strands and concrete in fire. Construction Building Materials 128:12-23, 2016. https: //doi.org/10.1016/j.conbuildmat.2016.10.016.

[21] A. Ajdukiewicz, J. Mames. Konstrukcje z betonu sprężonego. Wyd. 2 popr. Stowarzyszenie Producentów Cementu, Kraków, 2008. 